University of Warwick institutional repository: http://go.warwick.ac.uk/wrap This paper is made available online in accordance with publisher policies. Please scroll down to view the document itself. Please refer to the repository record for this item and our policy information available from the repository home page for further information.

To see the final version of this paper please visit the publisher's website. Access to the published version may require a subscription.

Author(s): David Tall

Article Title: A child thinking about infinity

Year of publication: 2001

Link to published version: http;//dx.doi.org/10.1016/S0732-

3123(01)00058-X

Publisher statement: None 


\title{
A Child Thinking About Infinity
}

\author{
David Tall \\ Mathematics Education Research Centre \\ University of Warwick \\ COVENTRY CV4 7AL
}

Young children's thinking about infinity can be fascinating stories of extrapolation and imagination. To capture the development of an individual's thinking requires being in the right place at the right time. When my youngest son Nic (then aged seven) spoke to me for the first time about infinity, I was fortunate to be able to tape-record the conversation for later reflection on what was happening. It proved to be a fascinating document in which he first treated infinity as a very large number and used his intuitions to think about various arithmetic operations on infinity. He also happened to know about "minus numbers" from earlier experiences with temperatures in centigrade. It was thus possible to ask him not only about arithmetic with infinity, but also about "minus infinity". The responses were thought-provoking and amazing in their coherent relationships to his other knowledge.

My research in studying infinite concepts in older students showed me that their ideas were influenced by their prior experiences. Almost always the notion of "limit" in some dynamic sense was met before the notion of one to one correspondences between infinite sets. Thus notions of "variable size" had become part of their intuition that clashed with the notion of infinite cardinals. For instance, Tall (1980) reported a student who considered that the limit of $n^{2} / n$ ! was zero because the top is a "smaller infinity" than the bottom. It suddenly occurred to me that perhaps I could introduce Nic to the concept of cardinal infinity to see what this did to his intuitions. My aim was to show him the correspondence between the set of even numbers, the set of odd numbers and the set of all (whole) numbers and to explore related ideas. He showed a great versatility in thinking, producing some surprising insights of his own.

Later he discussed the notion of infinity with his friends. He returned with a new view of infinity as a single large entity which is bigger than anything else and has no bigger number. The way in which he rationalised this with his earlier ideas involves a fascinating personal idea of the number line. The whole episode shows the amazing ability of a young child to deal with various infinite concepts and attempt to make the ideas fit together in coherent way-a task which reveals the endless fascination of the workings of the human brain. 


\section{Early Experience with Number}

Nic began his regular schooling at the age of four years and three months, because he was born at a time when the birthrate suddenly diminished and younger children went to school early to fill up the classes. At home for lunch in the winter, aged four years and six months, he heard the weatherman on television mention that the temperature would be down to "minus two degrees centigrade". He asked what "minus two" meant. Fortunately we had an outdoor thermometer and I took him outside and explained the scale, higher numbers being warmer, lower numbers colder; at zero degrees ice forms and snow falls instead of rain. He took easily to the idea and on the spur of the moment I showed him that if he started at 4 and counted down 3 , he ended at 1 , but if he started at 2 and counted down 3 he ended at -1 . "So?" he enquired in rather an unimpressed tone, as though what I had said was self-evident.

We did not speak of negative numbers again for some time, indeed, I had resolved that I would allow my children to have a normal school life so I only discussed mathematics when they specifically introduced a topic themselves.

Two months later, attending a parents' evening, I was amused to see that he had only one question marked wrong in the whole of his maths exercise book. After a session of "take-aways", for a special treat, the teacher had allowed him to invent the last sum himself. The teacher marked it wrong.

His writing at four and a half was ill-formed and virtually unreadable. but there for me to see was his sum. It read

$$
2 \downarrow 3=-1 .
$$

I was amazed. I explained to the teacher what he had written, but she seemed embarrassed to be talking to a university mathematician. Back at home I asked him if he was upset that the teacher had marked it wrong. "No," he said, with a dismissive tone of voice, "she didn't understand."

His fascination with numbers continued. About a year later as we walked into town he said, "Dad, how do you multiply minus numbers?" Again I was astonished. Having had experience of teaching negative numbers to older children in terms of debts, I suggested a system to by which he could borrow from me as long as he kept an IOU in his purse. When he counted up how much he had he must take away the IOUs to find the actual total. To do this, an IOU of 10p would be called minus 10p. We did a few typical sums, then I asked him if he would prefer me to take away 10p or minus 10p. This amused him so much he just laughed, it was so obvious, it was not worth an answer-clearly he would rather lose an IOU than money! 
I then set up a situation where he had been particularly good and I wanted to give him 50p reward, but I had no money in my pocket. I asked him how I could give him 50p. He immediately said, You could take away five of these minus tens. His face changed and he added the comment "Oh, so two minuses make a plus." This insight opened up to him the arithmetic with positive and negative numbers. As we walked, we played at sums in which he unerringly gave the right answers to quite complicated combinations of positive and negative numbers. With no further teaching he could add, subtract and multiply any combination of positive and negative numbers.

The whole conversation lasted less than the time it takes to walk into town, at most ten minutes. From that time on, Nic loved to challenge his elder brother Chris to a duel with "sums". Chris was far better at "tables" but Nic relished problems involving negative numbers. He particularly enjoyed sums like "5 take away minus 2 " which he immediately offered the answer "seven" whilst his older brother Chris stamped around in anger saying the answer must be "three", because "if you take something away, you gotta have less!"

He loved talking about big numbers too and was quite excited when he met the word "googol" (1 followed by a hundred 0's). We also discussed powers of ten, so that he knew that 102 was 100,103 is 1000 , and 10100 is a 1 followed by a hundred noughts. That he understood the concept of place value involved is evidenced by his humour about symbolism. When asked yet again to write down ten sums whose answer was 1, he replied by writing:

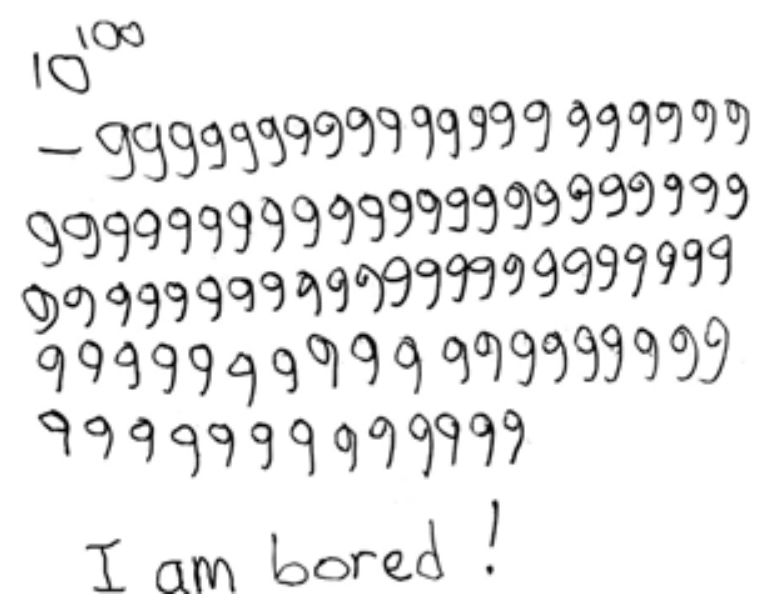

Nic's response to being asked to write a sum whose answer is 1 (There really are ninety nine 9s!)

\section{Talking about infinity}

At the age of seven years and one month, Nic came out with a comment that took me totally by surprise: 
"I've invented a number bigger than infinity."

We had never talked about infinity. I was so flabbergasted that I asked him if he minded my making a tape of what he said. This is part of the conversation that followed with Nic's comments in heavy type:

"A little bit earlier today you told me about a new number. What's it called?"

\section{"Infinity."}

"Who told you about infinity?"

"Chris." [His nine year old brother.]

"And where did he learn about it?"

\section{"1 don't know."}

"What is infinity."

"A very, very high number."

"How high is it?"

[ten seconds pause.]

\section{"Quite high."}

"Is it bigger than ten?"

\section{"Much bigger."}

"Bigger than a million?"

[firmly] "Bigger."

"Bigger than a googol?"

[still confident. but possibly with a questioning upturn in intonation] "Bigger (?)"

"What about a googol times a googol, is it bigger than that?"

[Nic thinks briefly:] "Well, ... I think that equals just about infinity."

"What is a googol, do you know?"

\section{"Well, ... that's also a very, very high number."}

"I see ... Is a billion, billion, billion, billion, infinity? ..." [very quietly:] "a billion, billion, billion, billion ..."

\section{"Well, I think it just about is."}

[This shows that Nic does not have the full array of large number concepts for a billion billion billion billion is $\left(10^{9}\right)^{4}=10^{36}$ which is much smaller than a googol. But he certainly has a feeling that some numbers are "very very big".] 
"You think it just about is. Do you know any numbers bigger than infinity?"

[firmly:] "Infinity and one."

"How much bigger than infinity is that?"

[firmly, with a questioning tone] "One."

"One? ... Is half infinity a big number?"

"Yes."

"You really think so?"

"Yes!"

"Is it bigger than infinity?"

"No."

"Tell me another number bigger than infinity."

[firmly] "Infinity and two."

"I see ... What about two infinity, is that much bigger than infinity?"

[Nic thinks for a moment.]

"Yes." [with a slight querying tone.]

"Tell me about minus infinity, have you ever heard about that?"

"Yes (?)" [He seems none too sure.]

[With a disbelieving tone.] "Who told you about minus infinity?"

"Um, I just thought of ... well, infinity is just quite the same as minus infinity."

"What do you mean the same?"

"Well, all you have to do is just add the minus on the end."

"Are they in the same place, infinity and minus infinity?"

"No!"

"Why not?"

[with great conviction and force:] "Because, if you take away infinity from infinity, you're left up with nothing, but if you take away two infinity from infinity, you get minus infinity."

[Approvingly] "That's very good! What happens if you divide infinity by infinity, what do you get then? ..." [four seconds pause.] "Let me put it another way, if you've got an infinite number of children and an infinite number of sweets, how many sweets does each child get?" 


\section{"One?"}

"Is it possible for them to get two each?"

[Nic begins to fidget, replying after seven seconds in a low tone.]

\section{"I don't guess so."}

\section{Comments}

Certain factors seem clear in Nic's remarks. He regarded infinity as a large number that can be added, subtracted and multiplied like any other number. His system includes positive and negative infinite numbers which are in different places. On a subsequent occasion I asked him about "one over infinity" and he was quite convinced that this was a "very, very small number". In effect he imagined a total arithmetic system including infinitely large and infinitely small numbers, though the infinite numbers were of the same kind as "very, very large numbers", "bigger than a googol", about as big as "a googol times a googol" or "a billion, billion, billion, billion". He was certainly affected by numbers which "sound large". A billion billion billion billion is $\left(10^{9}\right)^{4}=10^{36}$ (using the American definition now prevalent), which is much smaller than a googol, but sounds extremely impressive.

In retrospect I regret that I did not ask him about "infinity minus 1" which might have produced an interesting response but at least I asked him about "half infinity" which he still regarded as a "very very large number."

In secondary school children are often introduced to the symbol " $\infty$ " for infinity (possibly allowing both $+\infty$ and $-\infty$ ) but they are then cautioned that a full arithmetic is not possible with infinity because it leads to inevitable contradictions. The inconsistencies arising from using only one (positive) infinity are genuine, but alternative systems can be described with many infinite elements that have reciprocals which are infinitely small.

I was touched to notice the mind of one young child naturally extended his finite experience to infinite ideas of this kind. By contrast, his final remarks above show that the cardinal aspect of number, using flexible correspondences between infinite sets, was much more difficult for him to grasp.

Having researched how adolescents interpret infinity often in terms of potentially infinite processes or arbitrarily large numbers, I was aware that these intuitions clashed with the introduction of infinite cardinals. I decided to seize the moment and introduce Nic to the idea of comparing infinite sets. 


\section{Cardinal Infinities}

We have already seen that Nic had a sense of "infinity" being a "very high number" and that he did not think an infinite set of children and an infinite set of sweets could be arranged to give two sweets to each child. To begin talking about infinite correspondences, I started by attempting to establish the notion of the infinite set of numbers (which, to him, meant the whole numbers, $1,2,3, \ldots)$, as follows:

"Now let me write down the numbers, one, two, three, four, five, dot, dot, dot" [Writes 1, 2, 3, 4, 5, ..] "They're all the numbers."

"Yes."

How many numbers are there altogether? Not that I've written down, but how many numbers are there altogether ... a hundred numbers do you think? ... A million numbers? A googol numbers? How many do you think?"'

[Firmly:] "Infinity."

"Infinity numbers do you think?"

"Yes."

"I see. ... Do you know what an even number is?

"Yes."

"Can you tell me some even numbers?"

"Two, ..., four, ..., ten, ..., twenty."

“[...] How many even numbers do you think there are?"

"Mmmm. Treble infinity."

"Treble infinity?"

"Yes."

"What do you say treble infinity for? That's more than ... Is treble infinity more than infinity?"

"Yes."

"You say there are more even numbers than there are ordinary numbers?"

[Five seconds pause.]

"Well I thought you meant more numbers, ... how many even numbers there was?"

"I did mean how many even numbers are there."

"Ah, um, ah!" 
"And you said treble infinity. And treble infinity is more than infinity, isn't it?"

"Yes."

"But I mean, three isn't an even number is it?"

"No."

"Or five."

"No."

At this stage I tried a new attack.

"Let me do a pretend thing. Suppose I draw this shape here. And inside..."

\section{"Mmm."}

"... I put two four six eight, and imagine that's a bag and I put all the even numbers into that bag."

\section{"Yes."}

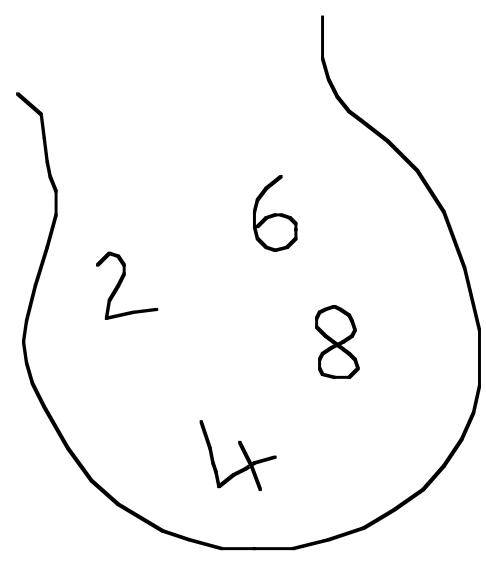

The bag of even numbers

"And imagine this is a bag and I put all the odd numbers in this bag. One, three, where do I put seven?" 


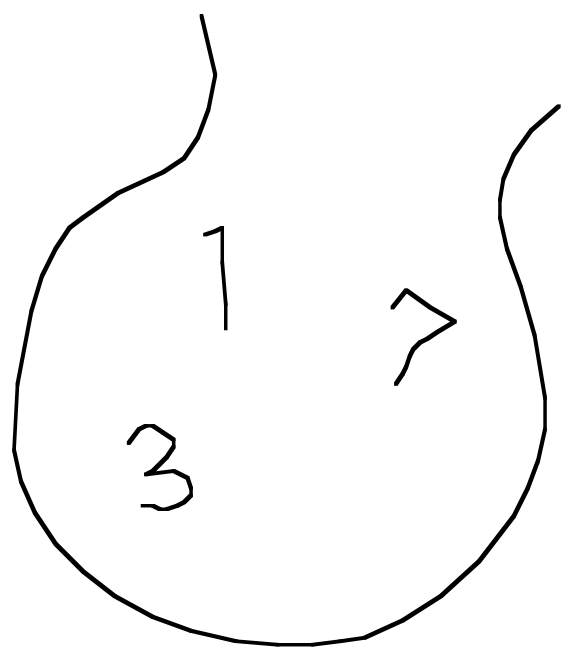

The bag of odd numbers

(Nic points to the odd bag.)

"That's right, in the odd bag. And where do I put twenty four?"

(Nic points to the even bag.)

"In the even bag. I'll write even over there and I'll write odd over there.

... Now, how many numbers do I put altogether in the even bag?"

\section{"Lots."}

"What do you mean by lots? ... A million? Twenty five? ... A googol?"

\section{"A lot. ... Six thousand billions."}

[Notice again the crazy delight in inventing a large sounding number...]

"Six thousand billion even numbers. ... What about six thousand billion and two?"

\section{"Yes?"}

[Notice here I had jumped from focusing on the number of even numbers to a specific even number. As it happened, this did not take us too far of the track.]

"Is that another even number?"

"Yes."

"So what about twelve billion? What about twenty four billion? Are they even numbers."

\section{"YES."}

"Do they go in that even set as well?"

\section{"YES."}

"So how many have I got in the even numbers all together?" 
[Five seconds pause.]

\section{"Quite a lot."}

"Would you say there was infinity in there?"

"Yes?" [with a slight querying tone. Here he was beginning to acquiesce to my suggestions without being sure of where I was going.]

"What about the odd numbers? How many numbers are there in the odd numbers? Would you say there's infinity in there?"

"No."

[Much later, on listening to the tape many times, it occurred to me that Nic was responding not to the number of elements in each set, but whether the 'number' infinity was in the set, but this possibility did not occur to me at the time.]

"Why not?"

"BECAUSE ... You can't make ... infinity into threes."

[I had no idea what this meant. I attempted to find out.]

"Why can't you?"

"Well, you can make ... if you can make a number into ... if you can make a number into twos, it's an even number, but if you can't it's an odd number."

[His meaning was still not clear to me, but I did not wish to lose the main thread, so I returned to asking how many odd numbers there were.]

"Yes, ... so how many odd numbers do I put in the odd bag? ... Where do I put two million and one ... which bag does that go in?"

(Nic points in the odd bag.)

"What about three million and one?"

(Nic again points to the odd bag.)

"What about one hundred and seventy seven, where does that go?"

(In the odd bag.)

"What about one million one hundred and seventy seven, where does that go?"

(In the odd bag.)

"You know a lot about odd numbers, don't you?"

"Yes!" [pleased by the compliment.]

"How many odd numbers are there? " 


\section{"Just about the same as even numbers."}

[The glimmerings of comparable infinite sets were appearing, so I tested this carefully by asking him to elaborate.]

"About the same as even numbers. Just about the same? Or is there one more,... or one less, ... or what?"

"Well, ... , there's one more or one less I should think."

"Which is it? ... Or perhaps there's the same?"

[He looked interested, so I decided to introduce him to new ideas - he had never met algebra before.]

"Can I show you a little trick?"

"Yes."

"Suppose I give a new name to a number. I'll call it $n, n$ for number, right?"

"Yes." [With a slight querying tone.]

"So ... now we do little tricks like this ..."

[Nic made encouraging noises.]

"Suppose $n$, the number $n$, is two, what is two $n \ldots$ two times $n$ ? If $n$ is two?"

\section{"Four."}

"If $n$ is three, what is two $n$ ?"

[Nic thinks for three seconds.] "Six."

"If $n$ is four, what is two $n$ ?"

[confidently] "Eight."

"OK. What is two $n$ plus one - if $n$ is three, what is two $n$ plus one."

[Five seconds pause.]

\section{"Five?"}

[Perhaps he was still thinking that $n$ is two.]

"No ... $n$ is three and you've got two $n$... plus one."

[Five seconds pause.]

\section{"Seven."}

"That's right!"

[My delight was uncontained and I pressed on to see if he could use the algebra to distinguish between "even" and "odd".] 
"Now I'm going to tell you something. You say that there's about the same even and odd ones, don't you?"

"Yes."

"... If $n$ is a number, then two $n$, is that an even or odd number? ... Two

$n \ldots$ think of some examples. If $n$ is three, what's two $n$ ?"

"Odd."

"Odd is it? ... $n$ is odd, three is odd, but what's two $n$ ?"

"Not odd."

"It's six, isn't it?"

"Yes."

"... What about if $n$ is four, what is two $n$ ?"

[Pause.]

"Eight."

"Is that odd or even?"

[Three seconds pause.] "Even!"

"Is two $n$ always even? ... Or is it sometimes odd?"

[Three seconds pause.] "Always even."

"Why is it always even?"

"Well, if you add an even number with an even number, you end up with an even number."

"Right."

"If You add an odd number and an odd number, you come up with an even number, but if you add an even number with an odd number, you come up with an odd number."

[chuckling:] "That's very good! Who told you that?"

"Mm. I worked it out myself."

[Laughing.] "Did you? 1 see! Do they tell you that sort of thing at school?"

"No."

"Well then, ... if $n$ is a whole number then two $n$, you say, is always even, do you?"

"Yes!"

"Because it's multiplying it by two, isn't it?" 
"Yes."

"What about two $n$ plus one, is that an even number or an odd number? Two $n$ plus one."

[Four seconds thought.]

\section{"An odd number."}

"Is it always an odd number?"

"Yes."

"So, if $n$ is any number then two $n$ is an even number ..."

"Yes."

"... and two $n$ plus one is an odd number "

"Yes!"

"I see. Now can I show you something?"

"Mm?"

"For every $n$ there is an even number, two $n$, and for every $n$ there is an odd number, two $n$ plus one."

[Nic not quite sure.] "Yes."

[Note here that I had made an unintended error which I did not notice at the time. By saying $2 n+1$, I had set up a correspondence between the natural number $n$ in $\{1,2,3, \ldots\}$ and a subset of the odd numbers, $2 n+1$ in $\{3,5,7, \ldots\}$. So I was "one out" in my intended correspondence between the natural numbers and th odd numbers. So in what followed, Nic could not have been precisely following the argument, although he might be following the broad sense of it.]

"So there's as many even numbers as odd numbers."

[Quietly.] "Mm."

"So there's not one extra is there? ... Or do you think there's one extra?"

"Well, I don't know..." [firmly] "I don't think there is one extra."

"You think they're the same, do you?"

"Yes."

"Well, let me show you this ... Do you know the name for infinity? Do you know how to write the name infinity?"

"No."

"Well, some people write infinity like that." [writes $\infty$ ] "Remember I went to Israel, don't you?" 
"Yes."

"In Israel, they have an alphabet and the first letter of their alphabet is called aleph and it's written like that." [writes $\$$ ]

"Mm."

"What's it called?"

"Aleph."

"Aleph. Now do you know how many whole numbers they say there is?"

"No?"

"Aleph, that's what they call it. The number of whole numbers is called aleph."

[Quietly, without much conviction:] "Yes."

"How many children are there in your class?"

"Thirty one."

"Thirty one, and so that's what they call the number of children in your class ... thirty one. ... How many whole numbers are there?"

"Aleph."

"Aleph. That's right! Well, how many even numbers are there then?"

"Aleph?"

“... and how many odd numbers are there?"

"Aleph."

[These questions were repeated to confirm the ideas.]

"So what happens if we add aleph plus aleph, what's the answer?"

[immediately] "Aleph!'”

[Feigning amazement:] "Aleph plus aleph equals aleph? Why is that?"

"Well it's just ... like so!" [With sudden conviction:] "Like nothing add nothing equals nothing!"

"It's the same is it?"

"Yes."

"So ... what happens if I have two aleph, is that the same as aleph?"

"Yes!"

"Why?"

"I don't know." 


\section{Reflections}

Did I do right to press on with infinite correspondences with a seven-year old? I don't know. He clearly enjoyed the experience as he wanted to continue with the conversation long after the two episodes described had finished. One thing is certain. I took a child with a consistent personal view of infinity as an arithmetic entity whereby

"infinity plus infinity is two infinity,"

and gave him a conflicting idea where

"aleph plus aleph is aleph."

In each case he used previous experiences to come to terms with the idea. In the first he reasoned that infinity and two infinity were different because "if you take infinity from infinity you get zero, but if you take two infinity from infinity you get minus infinity", an insight that amazed me at the time. In the latter case he reasoned that "aleph plus aleph equals aleph" was as reasonable as "nought plus nought equals nought", again a consideration I had not reckoned on.

\section{Interlude}

The following day we talked about infinity again. Nic remained confident. But in him there were the seeds of conflict. A week later he came to me and said

\section{"I don't believe infinity plus one is bigger than infinity any more "}

"What is it then?", I asked.

"Infinity," he replied. "I've been talking with my pals and we all think that you can't have bigger than infinity."

He was also under some pressure from his older brother Chris who regarded infinity as "going on forever" and so "you can't get past infinity" and "You can't have infinity plus one."

I was a little saddened. Perhaps I had also contributed to the collapse of his arithmetic system containing the infinitely large and small by my talk about the cardinal number aleph.

"But what about minus infinity?" I asked him, clutching at straws.

"That's the same as infinity," he affirmed.

I asked him to explain how it could be in view of his earlier ideas and he said:

"You can't get past infinity, but if you could, you would reach the negative numbers and keep going up." 
For him the number line was now circular with the endpoints at the same place.

"Aha!" the sophisticated mathematician might say, "he has now performed the one-point compactification of the number line by adding a single point at infinity “

Not so Such a sophisticated interpretation is as wrong as my earlier suggestion that he saw the number line as a "non-standard" number system. It is just as wrong as the interpretation that the only correct views of infinity are the cardinal and ordinal infinities of mathematicians.

When we try to grasp the mental idea of infinity we have only our experiences to use for interpretation For Nic his experiences were with positive and negative numbers and he extrapolated his ideas to encompass a "very, very big number" called infinity, My (perhaps illadvised) attempt to introduce him to the cardinal number concept and his conversations with his friends gave him alternative conflicting interpretations. When he was confronted with the position of infinity and minus infinity, his perceptive resolution, of the crisis was to put them in the same place, giving him a circular number line.

When we talk of "infinity and the mind" we should ask "whose mind?" As adults we have different experiences and subtly different views of infinity. As teachers we should be aware of the surprisingly sophisticated and complex ideas of the young that deserve to be treated on their own terms with respect. 